\title{
Potentially inappropriate prescribing and adverse drug reactions in the elderly: a population-based study
}

\author{
Khedidja Hedna ${ }^{1,2}$ - Katja M. Hakkarainen ${ }^{2,3}$ - Hanna Gyllensten ${ }^{2,4}$. \\ Anna K. Jönsson ${ }^{5} \cdot$ Max Petzold $^{6}$ • Staffan Hägg ${ }^{1,7}$
}

Received: 29 June 2015 / Accepted: 15 September 2015 / Published online: 26 September 2015

(C) The Author(s) 2015. This article is published with open access at Springerlink.com

\begin{abstract}
Purpose Potentially inappropriate prescriptions (PIPs) criteria are widely used for evaluating the quality of prescribing in elderly. However, there is limited evidence on their association with adverse drug reactions (ADRs) across healthcare settings. The study aimed to determine the prevalence of PIPs, defined by the Screening Tool of Older Persons' potentially inappropriate Prescriptions (STOPP) criteria, in the Swedish elderly general population and to investigate the association between PIPs and occurrence of ADRs.

Method Persons $\geq 65$ years old were identified from a random sample of 5025 adults drawn from the Swedish Total Population Register. A retrospective cohort study was conducted among 813 elderly with healthcare encounters in primary and specialised healthcare settings during a 3-month period in 2008. PIPs were identified from the Swedish Prescribed
\end{abstract}

Electronic supplementary material The online version of this article (doi:10.1007/s00228-015-1950-8) contains supplementary material, which is available to authorized users.

Khedidja Hedna

khedidja.hedna@liu.se

1 Division of Drug Research, Department of Medical and Health Sciences, Linköping University, Linköping, Sweden

2 Nordic School of Public Health NHV, Gothenburg, Sweden

3 EPID Research, Espoo, Finland

4 Division of Insurance Medicine, Department of Clinical Neuroscience, Karolinska Institute, Stockholm, Sweden

5 Department of Clinical Pharmacology and Department of Medical and Health Sciences, Linköping University, Linköping, Sweden

6 Centre for Applied Biostatistics, University of Gothenburg, Gothenburg, Sweden

7 Futurum, Jönköping County Council, Jönköping, Sweden
Drug Register, medical records and health administrative data. ADRs were independently identified by expert reviewers in a stepwise manner using the Howard criteria. Multivariable logistic regression examined the association between PIPs and ADRs.

Results Overall, 374 (46.0 \%) persons had $\geq 1$ PIPs and 159 (19.5\%) experienced $\geq 1$ ADRs during the study period. In total, $29.8 \%$ of all ADRs was considered caused by PIPs. Persons prescribed with PIPs had more than twofold increased odds of experiencing ADRs (OR 2.47; $95 \%$ CI 1.65-3.69). PIPs were considered the cause of $60 \%$ of ADRs affecting the vascular system, $50 \%$ of ADRs affecting the nervous system and $62.5 \%$ of ADRs resulting in falls.

Conclusion PIPs are common among the Swedish elderly and are associated with increased odds of experiencing ADRs. Thus, interventions to decrease PIPs may contribute to preventing ADRs, in particular ADRs associated with nervous and vascular disorders and falls.

Keywords Inappropriate prescribing $\cdot$ Elderly $\cdot$ Adverse drug reactions $\cdot$ Retrospective study $\cdot$ Medical records $\cdot$ Registries

\section{Background}

The rapid growth in the proportion of older population increases demands on healthcare systems worldwide [1]. Several factors contribute to the challenge of the care of the elderly, including comorbidities and chronic conditions often requiring multiple medications [2, 3], age-related physiological changes leading to increased sensitivity to drug effects [4] and limited evidence of drug effectiveness and safety in older and frail patients [5]. Previous studies have reported that up to $61 \%$ of older patients in hospital settings develop adverse drug reactions (ADRs) [6], and approximately half of them 
are potentially preventable [7]. Potentially inappropriate prescriptions (PIPs) may be defined as "the prescriptions that introduce a significant risk of an adverse drug related event when there is evidence for an equally or more effective alternative medication" [8]. PIPs have been reported as an important cause of iatrogenic morbidity [9], mortality [10] and increased healthcare costs [11].

Explicit prescribing criteria have been developed to raise prescribers' and other healthcare providers' awareness about inappropriate prescribing and to improve the quality of prescribing in the elderly $[12,13]$. The Screening Tool of Older Persons' potentially inappropriate Prescriptions (STOPP), published in 2008 [14], has been endorsed by researchers in different jurisdictions, in Europe and elsewhere, for evaluating the quality of prescribing of elderly patients with multiple chronic conditions [15-18]. However, evidence of an association between PIPs identified by STOPP criteria and the occurrence of ADRs is limited [19] and mainly studied in hospital settings [20-22]. As the majority of healthcare contacts of the elderly occur in primary care [23], we aimed to determine the prevalence of PIPs, defined by STOPP criteria, in the Swedish elderly general population, including all care settings, and to study the association between PIPs and occurrence of ADRs.

\section{Methods}

\section{Study design and study population}

Individuals older than 65 years were identified from a random sample of 5025 adult residents in the County Council of Östergötland, drawn from the Total Population Register of Statistics Sweden [24]. A retrospective cohort study was conducted using the medical data of older patients, who had at least one healthcare encounter in primary or specialised care over a 3-month period in 2008.

\section{Data sources}

Several data sources were linked using the personal identity number [25]. Data on prescribed medications were extracted from the Swedish Prescribed Drug Register (SPDR) [26]. The register includes dispensed prescribed drugs for outpatients, residential care and nursing homes, but excludes drugs administered in hospitals, and emergency drugs in residential care and nursing homes. Data on healthcare encounters were retrieved from the regional patient register (the Care Data Warehouse of Östergötland County), which includes administrative data on all inpatient and outpatient care provided in the county in all medical specialties and its coverage is considered full [27]. Based on the administrative care data, electronic medical records in all care units were reviewed during the study period. Sociodemographic characteristics were accessed from Statistics Sweden.

\section{Case assessment}

\section{Detection of PIPs}

The STOPP criteria include 65 instances of common PIPs, including drug-drug and drug-disease interactions, unnecessary therapeutic duplication and drugs which can increase the risks of cognitive decline and falls in older patients [14]. Patient medical data, including medical histories, diagnoses and current medications, were recorded by one research pharmacist. Prescribed medications were identified from the SPDR through the Anatomical Therapeutic Chemical (ATC) classification system. PIPs were assessed during 6 months, including 3 months prior the study period. The research pharmacist referred to the research team in the event of uncertainty regarding interpretation of the clinical data and application of the STOPP criteria.

\section{Detection of ADRs}

An ADR was defined according to the World Health Organisation as "a response to a drug which is noxious and unintended, and which occurs at doses normally used in man..." [28]. ADRs were detected in a stepwise manner. All suspected ADRs occurring during the study period were initially analysed by other research pharmacists than the one who identified PIPs. They extracted information from the medical records for the 3-month study period, 9 months before and 3 months after. Used triggers included symptoms indicating worsening health status [29], common drug/adverse event combinations [29] and drug-drug interactions [30]. A clinical pharmacologist and a senior pharmacist independently assessed the causality between the prescribed medications and the suspected ADRs using Howard algorithm [31]. Conflicting assessments were solved by consensus. Suspected ADRs with at least possible causality were considered ADRs. The seriousness of ADRs was assessed [32]. Finally, PIPs with causal contribution to the identified ADRs were considered.

\section{Statistical analysis}

The baseline characteristics of the study population included the number of prescribed medications, the level of healthcare use (defined by Diagnosis Related Group (DRG) weights [33]) 3 months prior to the study period and the most common morbidities. We estimated the prevalence of individuals with at least one PIP, with elderly individuals who had a healthcare encounter during the study period as the denominator. The 
most common PIPs (those occurring in at least ten individuals) and the proportion causing ADRs was reported.

The 3-month prevalence of individuals with ADRs and the proportion of ADRs considered as caused by PIPs were calculated. The ten most common organ system disorders and symptoms, as defined by the Medical Dictionary for Regulatory Activities (MedDRA) [34], were reported, and the proportion considered as caused by PIPs was calculated. Serious ADRs judged to be caused by PIPs were described.

The association between PIPs and ADRs was investigated with a multivariable logistic regression. The results were adjusted for age (65-74, 75-84, $\geq 85$ years), sex, number of dispensed prescribed medications $(0,1,2-5,6-9, \geq 10)$, level of healthcare use and use of multidose drug dispensing [35]. Data analysis was performed using Stata version 11.1 (StataCorp, TX). $P$ value of less than 0.05 was considered statistically significant.

Finally, a sensitivity analysis was performed without the 12 criteria that are excluded from the updated STOPP version (November 2014) [36].

\section{Ethical consideration}

The study was approved by the Regional Ethical Review Board in Gothenburg (no: 644-2008) according to the Swedish regulation. Informed consent of participants was not required as the retrospective study design did not affect the healthcare of included patients. Statistics Sweden replaced the personal identity numbers by a random serial number after the final data linkage and data were analysed anonymously.

\section{Results}

Data were collected from 813 elderly. The main characteristics of the study population are summarised in Table 1 . The median age was 75.0 years (range 65-98 years). In total, 66.7\% had encounters exclusively in primary care, and $7.3 \%$ was hospitalised 3 months prior to the study period. Overall, $25.2 \%$ of the study population was prescribed 6 to 9 medications and $12.0 \% \geq 10$ medications.

We found 607 PIPs prescribed to 374 persons (46.0 \%) (Table 2). The prevalence of PIPs was $42.8 \%$ among those with exclusively primary healthcare contacts, $52.4 \%$ among those with specialised healthcare and $66.1 \%$ among the elderly who were hospitalised at least once during the 3-month study period. Multivariable regression analysis showed that persons prescribed PIPs had more than twofold increased odds to experience ADRs (odds ratio (OR) 2.47, $95 \%$ confidence interval (CI) $1.65-3.69) ; p<0.001$ ), compared to that in persons without PIPs.

The most common PIPs are described in Table 3. In total, $10.5 \%$ of PIPs caused ADRs (Table 3). The percentage of
Table 1 Study population characteristics $(n=813)$

\begin{tabular}{ll}
\hline Characteristics & $n(\%)$ \\
\hline Age (years) & \\
Median (range) & $75.0(65-98)$ \\
$\quad 65-74$ & $401(49.3)$ \\
$\quad 75-84$ & $289(35.6)$ \\
$\quad \geq 85$ & $123(15.1)$ \\
Sex & \\
Female & $458(56.3)$ \\
Dispensed prescribed medications ${ }^{\mathrm{a}}$ & \\
Median (range) & $4.0(0-20)$ \\
$\quad 0$ & $90(11.1)$ \\
$\quad 1$ & $72(8.9)$ \\
$\quad 2-5$ & $384(42.8)$ \\
$\quad 6-9$ & $205(25.2)$ \\
$\quad \geq 10$ & $98(12.0)$ \\
Patients prescribed cardiovascular medications & \\
Patients prescribed psychotropic medications & \\
Use of multiple drug dispensing & $595(73.2)$ \\
Level of healthcare use & $278(34.2)$ \\
Primary care & $85(10.4)$ \\
Specialised (outpatient or inpatient) care & \\
Hospitalisation & $542(66.7)$ \\
Morbidities & $271(33.3)$ \\
Hypertension & $59(7.3)$ \\
Diabetes & \\
Ischemic heart disease & $358(44.0)$ \\
Mental and behavioural disorders & $158(19.4)$ \\
Heart failure & $147(18.1)$ \\
Osteoarthritis & $140(17.2)$ \\
Chronic obstructive pulmonary disease & $85(10.5)$ \\
Dementia & $83(10.2)$ \\
\hline
\end{tabular}

${ }^{\mathrm{a}}$ Three months prior to the study period

${ }^{\mathrm{b}}$ Anatomical Therapeutic Chemical code $\mathrm{C}$

${ }^{\mathrm{c}}$ Anatomical Therapeutic Chemical code N05 and N06

${ }^{\mathrm{d}}$ Defined by DRG weights

PIPs considered causing ADRs was the highest for vasodilators in persons with persistent postural hypotension ( $92.3 \%$ of PIPs causing ADRs), prolonged use of neuroleptics (46.2 \%), first-generation antihistamines $(25.0 \%)$ and benzodiazepines $(23.3 \%)$ in those prone to fall.

Overall, 245 ADRs were identified in 159 persons (19.6\%), of which 73 were considered as caused by PIPs (29.8\% of all ADRs). PIPs were considered the cause of a high percentage of ADRs affecting the vascular and nervous systems (60.0 and $50.0 \%$, respectively) (Fig. 1). Moreover, $62.5 \%$ of ADRs resulting in falls were considered as caused by inappropriate use of benzodiazepines (Fig. 2).

Twelve serious ADRs were identified; among them, eight were considered caused by PIPs mainly by antipsychotic and 
Table 2 Number of potentially inappropriate prescriptions in persons $(n=813)$

\begin{tabular}{ll}
\hline Number of PIPs/person & $n(\%)$ \\
\hline Mean (range) & $0.76(0-9)$ \\
Number of persons with $\geq 1$ PIPs & $374(46.0)$ \\
1 & $221(27.2)$ \\
2 & $102(12.6)$ \\
3 & $28(3.4)$ \\
$\geq 4$ & $23(2.8)$ \\
PIPs in persons using only primary care & $226(42.8)$ \\
PIPs in persons using specialised healthcare & $148(52.4)$ \\
PIPs in hospitalised persons & $33(66.1)$ \\
\hline
\end{tabular}

PIP potentially inappropriate prescriptions

non-steroidal anti-inflammatory drugs (Supplement 1). One death was judged to be caused by the long-term use of nitrazepam.

\section{Sensitivity analysis}

When the analyses were limited to the 53 criteria included in the updated STOPP version [36], 270 (33.2\%) elderly persons had at least one PIP, $24.9 \%$ of ADRs were considered as caused by PIPs, and PIPs were significantly associated with the occurrence of ADRs (OR 2.57, $95 \%$ CI 1.75-3.77, $p<0.001$ ).

\section{Discussion}

Nearly half of patients across care settings were prescribed with one or more PIPs during a 3-month period. Moreover, one third of ADRs were considered caused by PIPs, and elderly who were prescribed with PIPs had over twofold increased odds to experience ADRs.

Our findings indicate that PIPs are common among patients in both primary and specialised healthcare. The prevalence of PIPs in studies using the STOPP criteria has ranged between 21 and $79 \%$, depending on the study setting and design [19]. In accordance with a Spanish study [37], our PIP prevalence was higher in specialised care compared to that in primary care. Persons using more advanced care probably have more complex comorbidities, which have been associated with PIPs [38]. However, elderly in specialised care may not be representative of the elderly population as a whole. As the majority of elderly use mainly primary care, the understanding of PIPs in primary care must be improved. Furthermore, the validity of detecting PIPs among the elderly in the general population should be investigated.

The most frequent PIPs in our study partially differed from common PIPs in hospital-based studies [19, 20, 39, 40]. Similarly to studies conducted in hospital settings [19], the longterm use of long-acting benzodiazepines and medications increasing the risk of fall (such as benzodiazepines, opiates and first-generation antihistamines) were among the most

Table 3 Most common potentially inappropriate prescriptions

\begin{tabular}{|c|c|c|}
\hline Criterion & $n(\%)$ & $\begin{array}{l}n(\%) \text { causing } \\
\text { ADRs }\end{array}$ \\
\hline Aspirin with no history of coronary, cerebral or peripheral arterial symptoms or occlusive arterial event & $154(18.9)$ & $7(6.5)$ \\
\hline Benzodiazepines in those prone to fall & $43(5.4)$ & $10(23.3)$ \\
\hline NSAID with moderate-severe hypertension & $41(5.0)$ & $1(2.4)$ \\
\hline Long-term long-acting benzodiazepines & $37(4.6)$ & $3(8.1)$ \\
\hline Prolonged use ( $>1$ week) of first generation antihistamines & $28(3.4)$ & $7(25.0)$ \\
\hline Use of long-term powerful opiates as first-line therapy for mild-moderate pain & $27(3.3)$ & $0(0)$ \\
\hline Long-term opiates in those with recurrent falls & $26(3.2)$ & $6(23.1)$ \\
\hline Long-term (i.e. $>1$ month) neuroleptics as long-term hypnotics & $26(3.2)$ & $12(46.2)$ \\
\hline Oestrogens without progestogen in patients with intact uterus & $23(2.8)$ & $0(0)$ \\
\hline Long-term corticosteroids ( $>3$ months) as monotherapy for rheumatoid arthritis or osteoarthritis & $19(2.3)$ & $2(10.5)$ \\
\hline Aspirin at dose $>150 \mathrm{mg} /$ day & $17(2.1)$ & 0 \\
\hline Long-term use of NSAID ( $>3$ months) for relief of mild joint pain in osteoarthritis & $14(1.7)$ & 0 \\
\hline Vasodilator drugs known to cause hypotension in those with persistent postural hypotension & $13(1.6)$ & $12(92.3)$ \\
\hline $\begin{array}{l}\text { Systemic corticosteroids instead of inhaled corticosteroids for maintenance therapy in moderate-severe } \\
\text { COPD }\end{array}$ & $12(1.5)$ & 0 \\
\hline First-generation antihistamines in those prone to fall & $11(1.4)$ & $1(9.1)$ \\
\hline Neuroleptic drugs in those prone to fall & $10(1.2)$ & 0 \\
\hline Total & $\begin{array}{l}607 \text { PIPs }(374 \\
\text { persons })\end{array}$ & $64(10.5)$ \\
\hline
\end{tabular}

$A D R$ adverse drug reaction, NSAID non-steroidal anti-inflammatory drugs, COPD chronic obstructive pulmonary disease 
Fig. 1 Organs affected by adverse drug reactions and the proportion considered by potentially inappropriate prescriptions

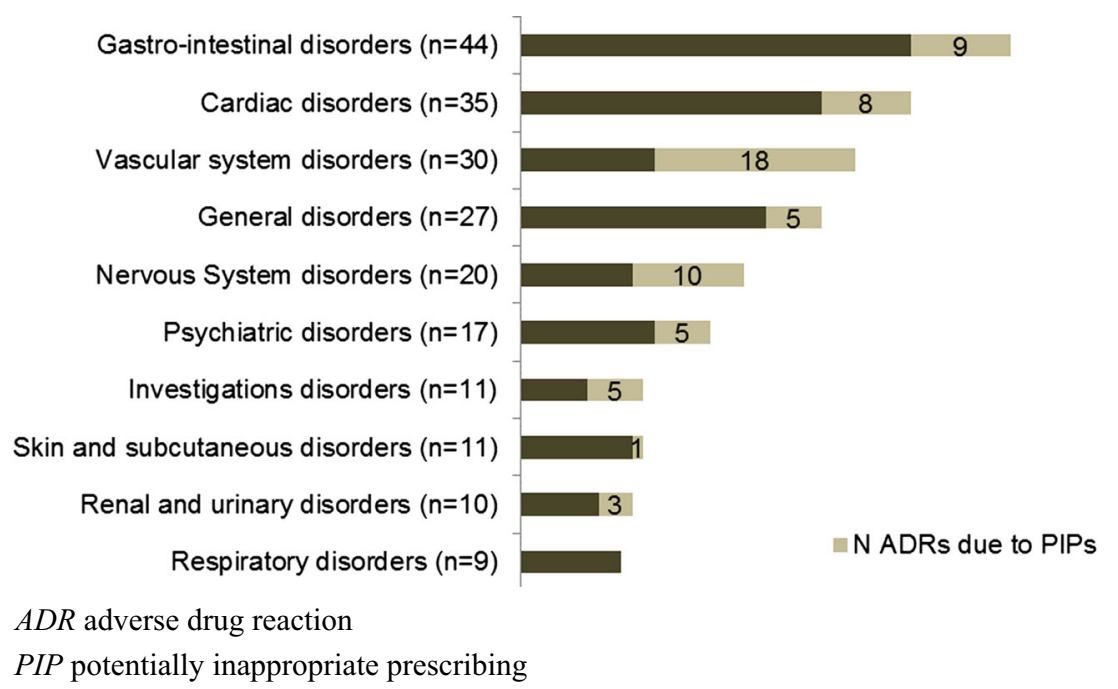

common PIPs in our study. However, while some PIPs, such as proton-pump inhibitors for peptic ulcer at full therapeutic dosage for $>8$ weeks, were frequently reported among the most common PIPs [20, 39, 40], they were rarely reported in our study. Nonetheless, some frequently reported PIPs in our study, such as the inappropriate prescribing of aspirin, were rarely reported in studies conducted exclusively in hospital settings [40]. The variation in the most common PIPs between studies is, in addition to care settings, probably explained by differing prescribing patterns and clinical practice guidelines, prescribing regulation, population characteristics and disease burden [40-42]. For example, the higher frequency of inappropriate prescribing of aspirin in our study compared to that in previous studies may be due to the commonness of aspirin as an over-thecounter medication in other countries [43], underestimating its inappropriate use in studies using exclusively prescription data.

We found a large part of PIPs associated with ADRs involving medications that increase the risk of falls, such as benzodiazepines, opiates and vasodilators, which indicate that decreasing PIPs could contribute towards fall prevention.
Though falls are considered multifactorial [44], our study found a high percentage of falls (or associated symptoms such as dizziness and orthostatic hypotension) caused by PIPs and, thus, considered as potentially preventable. Patients may be unable to recognise ADRs, such as hypotension or dizziness, or not report them to their healthcare givers, increasing the risk of experiencing falls as ADRs, if the medication regimen is not adjusted [45]. Medication review by prescribers and other healthcare professionals, including a comprehensive falls assessment, could decrease such PIPs, as shown by a prescribing education programme for primary care physicians, which significantly reduced the risk of fall among elderly patients [46]. Vasodilators appear particularly strongly associated with falls or associated symptoms; as in our study, the percentage of PIPs associated with ADRs was the highest for vasodilators in those with persistent postural hypotension. Safety issues of medications with repeat prescribing including vasodilators have also been previously warranted [47].

Our study including all care settings found elderly with PIPs having significantly increased odds of experiencing
Fig. 2 The most common symptoms of adverse drug reactions and the proportion caused by potentially inappropriate prescriptions

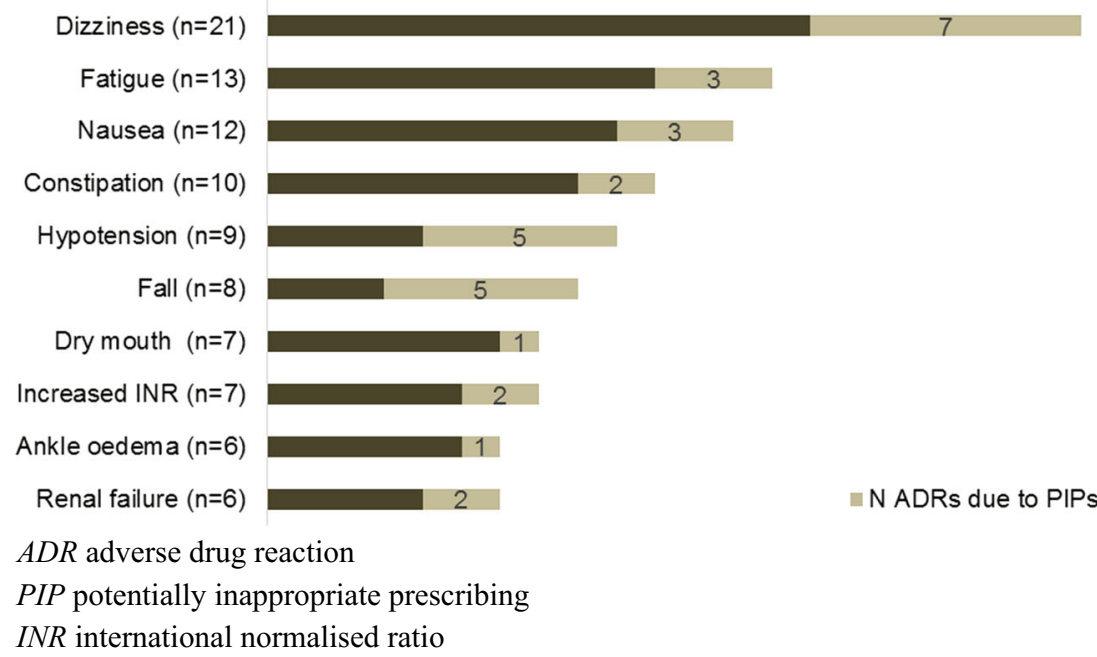


ADRs, demonstrating that PIPs cause potentially preventable morbidity across care settings. Most ADRs due to PIPs in our study were non-serious, while some previous studies have mainly focused on the associations between PIPs and serious adverse outcomes, such as hospitalisation and death [10, 48]. However, even mild ADRs are important to consider as they are associated with lower quality of life, may increase the visits to general practitioners and cause prescribing cascades to treat symptoms of unrecognised ADRs [49]. Although we identified few serious ADRs due to PIPs across care settings, the ADRs included one fatal case due to long-term use of long-acting benzodiazepines, highly recognised to be inappropriate in the elderly. This suggests that improving the quality of prescribing could also prevent some fatal ADRs.

The association between PIPs and ADRs remained significant after limiting the analysis exclusively to the STOPP criteria included in the updated version. Thus, excluding certain criteria in the updated version appears relevant. We should emphasise, however, that the updated version was extended to 76 criteria, among them 23 criteria not listed in the first version, including some general ones as "Any drug prescribed without an evidence-based clinical indication or beyond the recommended duration". Moreover, the new version considers the use of benzodiazepines for more than 4 weeks as inappropriate, which was found in $23.2 \%$ of our study population. Therefore, our estimation of PIPs prevalence may not be an overestimation, although the most common inappropriate drugs would differ between the two versions.

\section{Strengths and limitations}

Our study is the first that investigated the association between PIPs according to STOPP criteria and ADRs among a representative sample of the general elderly population. Nevertheless, our findings should be interpreted with some limitations in mind. STOPP criteria are widely used to evaluate the quality of prescribing in the elderly. However, in some cases, medications classified as potentially inappropriate may be appropriate considering individual patient's health condition. Yet, the assessment of PIPs' causality or contribution to the detected ADR was based on a validated causality assessment algorithm [31]. The SPDR includes prescriptions in outpatients and nursing homes, and we could not include prescriptions during hospitalisations and emergency drugs in nursing homes and specialised care. However, only $7 \%$ of the study population had short hospitalisation episodes during the study period, which also raises the question about the generalisability of studies conducted only in hospital settings. We were also unable to stratify our regression analysis by the type of residence, due to unavailability of these data. Although previous studies have found significant differences in PIPs by type of residence [37], the potentially small number of elderly living in nursing homes [50] would, however, limit interpreting such stratified analysis.

The study was conducted across different healthcare organisations, with different quality and quantity of medical record data. Some PIP criteria were impossible to evaluate in cases with insufficient clinical information and history (e.g. information about an intact uterus). However, our method of assessment of cases, based on symptoms, biological and clinical data, allowed the detection of ADRs that were not recognised or reported as such in the medical records. However, symptoms of ADRs not communicated by patients or not recorded by care providers in the medical records could not be detected in this study.

While we adjusted our regression model with known factors associated with PIPs and ADRs, some confounders might have been undetected. Further, we purposefully did not consider the new criteria in the sensitivity analysis as they are based on new recommendations that may be irrelevant to apply to prescriptions in 2008 .

\section{Implications}

The STOPP criteria may be a useful tool for screening and identifying potential ADRs in older people across healthcare settings. While previous studies have found PIPs detected with the STOPP criteria significantly associated with ADRs among hospitalised patients [21], our study extend the evidence on their use to detect ADRs across healthcare settings. However, the applicability of the STOPP criteria in clinical practice and community pharmacy needs to be established. There is an ongoing study to integrate the STOPP criteria in an electronic automated format [51]. Nevertheless, integrating the STOPP criteria in the medication use reviews in community pharmacies and general practices requires an access to complete patient clinical data and a learning time to familiarise with them [19].

Based on our results, the STOPP criteria seem to be particularly sensitive to detect nervous and vascular disorders and falls. However, a better understanding of the two thirds of ADRs due to medications not listed in the PIPs criteria, including over-the-counter medications is needed, as they have been associated with increased morbidity and hospitalisations [52].

Reducing both PIPs and ADRs among the elderly will require system interventions to routinely assess drug appropriateness, effectiveness, safety and adherence, while balancing the risk of underuse of beneficial medications [53]. Moreover, there is a need for valid patient-centred prescribing evaluation tools across care settings to track patients' perceived adverse outcomes and to engage them in monitoring their medications [53]. Improving the quality of prescribing requires a collaboration of prescribers and other healthcare professionals and a 
better continuity of care of patients with chronic conditions [54].

\section{Conclusion}

In conclusion, PIPs are common among the Swedish elderly and are associated with twofold increased odds to experience ADRs. The PIP criteria defined by STOPP are not a substitute for clinical assessment and judgement, but they may encourage clinicians to consider medications as a possible cause of adverse health outcomes, in particular nervous system and vascular disorders and falls. Thus, interventions to decrease PIPs may contribute to preventing ADRs among the elderly.

Acknowledgments The study was conducted as part of the project Drug-Related Morbidity in Sweden (DRUMS). The project was funded through unrestricted grants from The National Corporation of Swedish Pharmacies (Apoteket AB), Linköping University, Östergötland County Council and Region Västra Götaland. Persons other than the authors who substantially contributed to the work: are Anders Carlsten (docent, Nordic School of Public Health NHV/Medical Products Agency), Clas Rehnberg (professor, Nordic School of Public Health NHV/Karolinska Institutet) and Karolina Andersson Sundell (docent, Nordic School of Public Health NHV/University of Gothenburg) who contributed to the study design. Ingela Jacobsson (BScRN, County Council of Östergötland), Ellinor Ottosson (MScPharm, Nordic School of Public Health NHV), Josefina Lindstén (MScPharm, Nordic School of Public Health NHV), Johnny Pettersson (MSc, Nordic School of Public Health NHV), Parshin Saadatirad (MScPharm, Nordic School of Public Health NHV), Staffan Svensson (MD PhD, Angered Family Medicine Unit), Karin Tunér (MScPharm, Nordic School of Public Health NHV/Region Halland), Annika Yeiter (MScMed, Nordic School of Public Health NHV) and Tatiana Zverkova Sandström (TZS) (BSocSc, Nordic School of Public Health NHV) who contributed to the data collection. TZS contributed to the data management.

Authors' contributions All authors were responsible for the study concept and design. $\mathrm{KH}, \mathrm{KMH}, \mathrm{HG}, \mathrm{AJ}$ and $\mathrm{SH}$ acquired the data. $\mathrm{KH}$ and MP were responsible for statistical analysis. All authors interpreted the data. $\mathrm{KH}$ drafted the manuscript and all authors contributed with critical revision of the manuscript. All authors read and approved the final manuscript.

\section{Compliance with ethical standards}

Ethics approval The study was approved by the Regional Ethical Review Board in Gothenburg (no: 644-2008) according to the Swedish regulation.

Consent to participate Informed consent of participants was not required as the retrospective study design did not affect the healthcare of included patients. Statistics Sweden replaced the personal identity numbers by a random serial number after the final data linkage and data were analysed anonymously.

Conflict of interest The authors declare that they have no competing interests.
Open Access This article is distributed under the terms of the Creative Commons Attribution 4.0 International License (http:// creativecommons.org/licenses/by/4.0/), which permits unrestricted use, distribution, and reproduction in any medium, provided you give appropriate credit to the original author(s) and the source, provide a link to the Creative Commons license, and indicate if changes were made.

\section{References}

1. World Health Organization WHO (2011) Global health and aging. US National Institute of Aging

2. Maher RL, Hanlon J, Hajjar ER (2014) Clinical consequences of polypharmacy in elderly. Expert Opin Drug Saf 13:57-65

3. Boyd CM, Darer J, Boult C, Fried LP, Boult L, Wu AW (2005) Clinical practice guidelines and quality of care for older patients with multiple comorbid diseases: implications for pay for performance. JAMA 294:716-724

4. Corsonello A, Pedone C, Incalzi RA (2010) Age-related pharmacokinetic and pharmacodynamic changes and related risk of adverse drug reactions. Curr Med Chem 17:571-584

5. Konrat C, Boutron I, Trinquart L, Auleley GR, Ricordeau P, Ravaud P (2012) Underrepresentation of elderly people in randomised controlled trials. The example of trials of 4 widely prescribed drugs. PLoS One 7:e33559

6. Krahenbuhl-Melcher A, Schlienger R, Lampert M, Haschke M, Drewe J, Krahenbuhl S (2007) Drug-related problems in hospitals: a review of the recent literature. Drug Saf 30:379-407

7. Hakkarainen KM, Hedna K, Petzold M, Hagg S (2012) Percentage of patients with preventable adverse drug reactions and preventability of adverse drug reactions - a meta-analysis. PLoS One 7:e33236

8. Hanlon JT, Schmader KE, Ruby CM, Weinberger M (2001) Suboptimal prescribing in older inpatients and outpatients. J Am Geriatr Soc 49:200-209

9. Passarelli MC, Jacob-Filho W, Figueras A (2005) Adverse drug reactions in an elderly hospitalised population: inappropriate prescription is a leading cause. Drugs Aging 22:767-777

10. Lau DT, Kasper JD, Potter DE, Lyles A, Bennett RG (2005) Hospitalization and death associated with potentially inappropriate medication prescriptions among elderly nursing home residents. Arch Intern Med 165:68-74

11. Bradley MC, Fahey T, Cahir C, Bennett K, O'Reilly D, Parsons C, Hughes CM (2012) Potentially inappropriate prescribing and cost outcomes for older people: a cross-sectional study using the Northern Ireland Enhanced Prescribing Database. Eur J Clin Pharmacol 68:1425-1433

12. Dimitrow MS, Airaksinen MS, Kivela SL, Lyles A, Leikola SN (2011) Comparison of prescribing criteria to evaluate the appropriateness of drug treatment in individuals aged 65 and older: a systematic review. J Am Geriatr Soc 59:1521-1530

13. Corsonello A, Onder G, Abbatecola AM, Guffanti EE, Gareri P, Lattanzio F (2012) Explicit criteria for potentially inappropriate medications to reduce the risk of adverse drug reactions in elderly people: from Beers to STOPP/START criteria. Drug Saf 35(Suppl 1):21-28

14. Gallagher P, Ryan C, Byrne S, Kennedy J, O'Mahony D (2008) STOPP (Screening Tool of Older Person's Prescriptions) and START (Screening Tool to Alert doctors to Right Treatment). Consensus validation. Int J Clin Pharmacol Ther 46:72-83

15. Liu CL, Peng LN, Chen YT, Lin MH, Liu LK, Chen LK (2012) Potentially inappropriate prescribing (IP) for elderly medical inpatients in Taiwan: a hospital-based study. Arch Gerontol Geriatr 55: $148-151$ 
16. Pyszka LL, Seys Ranola TM, Milhans SM (2010) Identification of inappropriate prescribing in geriatrics at a Veterans Affairs hospital using STOPP/START screening tools. Consult Pharm 25:365-373

17. Windsant-van V, den Tweel AM, Verduijn MM, Derijks HJ, van Marum RJ (2012) Detection of inappropriate medication use in the elderly; will the STOPP and START criteria become the new Dutch standards? Ned Tijdschr Geneeskd 156:A5076

18. Alfaro Lara ER, Vega Coca MD, Galvan Banqueri M, Marin Gil R, Nieto Martin MD, Perez Guerrero C, Ollero Baturone M, SantosRamos B (2012) Selection of tools for reconciliation, compliance and appropriateness of treatment in patients with multiple chronic conditions. Eur J Intern Med 23:506-512

19. Hill-Taylor B, Sketris I, Hayden J, Byrne S, O'Sullivan D, Christie R (2013) Application of the STOPP/START criteria: a systematic review of the prevalence of potentially inappropriate prescribing in older adults, and evidence of clinical, humanistic and economic impact. J Clin Pharm Ther 38:360-372

20. Hamilton H, Gallagher P, Ryan C, Byrne S, O'Mahony D (2011) Potentially inappropriate medications defined by STOPP criteria and the risk of adverse drug events in older hospitalized patients. Arch Intern Med 171:1013-1019

21. Gallagher P, O'Mahony D (2008) STOPP (Screening Tool of Older Persons' potentially inappropriate Prescriptions): application to acutely ill elderly patients and comparison with Beers' criteria. Age Ageing 37:673-679

22. Cahir C, Bennett K, Teljeur C, Fahey T (2014) Potentially inappropriate prescribing and adverse health outcomes in community dwelling older patients. Br J Clin Pharmacol 77:201-210

23. The European Observatory on Health Systems and Policies (2008) Managing chronic conditions. Experience in eight countries

24. Hakkarainen KM, Gyllensten H, Jonsson AK, Andersson Sundell K, Petzold M, Hagg S (2014) Prevalence, nature and potential preventability of adverse drug events - a population-based medical record study of 4970 adults. Br J Clin Pharmacol 78:170-183

25. Ludvigsson JF, Otterblad-Olausson P, Pettersson BU, Ekbom A (2009) The Swedish personal identity number: possibilities and pitfalls in healthcare and medical research. Eur J Epidemiol 24: 659-667

26. Wettermark B, Hammar N, Fored CM, Leimanis A, Otterblad Olausson P, Bergman U, Persson I, Sundstrom A, Westerholm B, Rosen M (2007) The new Swedish Prescribed Drug Registeropportunities for pharmacoepidemiological research and experience from the first six months. Pharmacoepidemiol Drug Saf 16: 726-735

27. Wirehn AB, Karlsson HM, Carstensen JM (2007) Estimating disease prevalence using a population-based administrative healthcare database. Scand J Public Health 35:424-431

28. World Health Organization (1972) International drug monitoring: the role of national centres

29. Morimoto T, Gandhi TK, Seger AC, Hsieh TC, Bates DW (2004) Adverse drug events and medication errors: detection and classification methods. Qual Saf Health Care 13:306-314

30. Bottiger Y, Laine K, Andersson ML, Korhonen T, Molin B, Ovesjo ML, Tirkkonen T, Rane A, Gustafsson LL, Eiermann B (2009) SFINX-a drug-drug interaction database designed for clinical decision support systems. Eur J Clin Pharmacol 65:627-633

31. Howard RL, Avery AJ, Howard PD, Partridge M (2003) Investigation into the reasons for preventable drug related admissions to a medical admissions unit: observational study. Qual Saf Health Care 12:280-285

32. Edwards IR, Aronson JK (2000) Adverse drug reactions: definitions, diagnosis, and management. Lancet 356:1255-1259

33. The National Board of Health and Welfare Diagnosis. Related groups [In Swedish]. http://www.socialstyrelsen.se/ klassificeringochkoder/norddrg. Accessed 29 June 2015
34. Medical Dictionary for Regulatory Activities (2011) Introductory guide MedDRA version 14.0, document MSSO-DI-6003-14.0.0, Medical Dictionary for Regulatory Activities. Geneva

35. Belfrage B, Koldestam A, Sjoberg C, Wallerstedt SM (2014) Prevalence of suboptimal drug treatment in patients with and without multidose drug dispensing - a cross-sectional study. Eur J Clin Pharmacol 70:867-872

36. O'Mahony D, O'Sullivan D, Byrne S, O'Connor MN, Ryan C, Gallagher P (2015) STOPP/START criteria for potentially inappropriate prescribing in older people: version 2. Age Ageing 44:213218

37. Conejos Miquel MD, Sánchez Cuervo M, Delgado Silveira E, Sevilla Machuca I, González-Blazquez S, Montero Errasquin B, Cruz-Jentoft AJ (2010) Potentially inappropriate drug prescription in older subjects across health care settings. Eur Geriatr Med 1:9-14

38. Ryan C, O'Mahony D, Kennedy J, Weedle P, Byrne S (2009) Potentially inappropriate prescribing in an Irish elderly population in primary care. Br J Clin Pharmacol 68:936-947

39. Garcia-Gollarte F, Baleriola-Julvez J, Ferrero-Lopez I, Cruz-Jentoft AJ (2012) Inappropriate drug prescription at nursing home admission. J Am Med Dir Assoc 13:83.e9-83.15

40. Gallagher P, Lang PO, Cherubini A, Topinkova E, Cruz-Jentoft A, Montero Errasquin B, Madlova P, Gasperini B, Baeyens H, Baeyens JP, Michel JP, O'Mahony D (2011) Prevalence of potentially inappropriate prescribing in an acutely ill population of older patients admitted to six European hospitals. Eur J Clin Pharmacol 67:1175-1188

41. Fialova D, Onder G (2009) Medication errors in elderly people: contributing factors and future perspectives. Br J Clin Pharmacol 67:641-645

42. European Commission (2012) Europeans of retirement age: chronic diseases and economic activity http://ec.europa.eu/health/major chronic diseases/docs/rivm_report retirement_en.pdf. Accessed 09 April 2015

43. Association of the European Self-Medication Industry (2015) http://www.aesgp.eu/facts-figures/otc-ingredients/. Accessed 26 June 2015

44. Deandrea S, Lucenteforte E, Bravi F, Foschi R, La Vecchia C, Negri E (2010) Risk factors for falls in community-dwelling older people: a systematic review and meta-analysis. Epidemiology 21:658-668

45. Weingart SN, Gandhi TK, Seger AC, Seger DL, Borus J, Burdick E, Leape LL, Bates DW (2005) Patient-reported medication symptoms in primary care. Arch Intern Med 165:234-240

46. Pit SW, Byles JE, Henry DA, Holt L, Hansen V, Bowman DA (2007) A Quality Use of Medicines program for general practitioners and older people: a cluster randomised controlled trial. Med J Aust 187:23-30

47. De Smet PA, Dautzenberg M (2004) Repeat prescribing: scale, problems and quality management in ambulatory care patients. Drugs 64:1779-1800

48. Klarin I, Wimo A, Fastbom J (2005) The association of inappropriate drug use with hospitalisation and mortality: a population-based study of the very old. Drugs Aging 22:69-82

49. Rochon PA, Gurwitz JH (1997) Optimising drug treatment for elderly people: the prescribing cascade. BMJ 315:1096-1099

50. The Committee for Collaboration Between Östergötland Region and Municipalities in Östergötland (2011) Elderly report [In Swedish]

51. European Commission (2014) Development and clinical trials of a new software engine for the assessment and optimization of drug and non-drug therapy in older persons (SENATOR). http://ec. europa.eu/research/health/medical-research/human-developmentand-ageing/projects/senator en.html. Accessed 26/06/2015

52. Schmiedl S, Rottenkolber M, Hasford J, Rottenkolber D, Farker K, Drewelow B, Hippius M, Salje K, Thurmann P (2014) Selfmedication with over-the-counter and prescribed drugs causing 
adverse-drug-reaction-related hospital admissions: results of a prospective, long-term multi-centre study. Drug Saf 37:225-235

53. Steinman MA, Handler SM, Gurwitz JH, Schiff GD, Covinsky KE (2011) Beyond the prescription: medication monitoring and adverse drug events in older adults. J Am Geriatr Soc 59:1513-1520
54. Chu HY, Chen CC, Cheng SH (2012) Continuity of care, potentially inappropriate medication, and health care outcomes among the elderly: evidence from a longitudinal analysis in Taiwan. Med Care 50:1002-1009 